\title{
Young people empathising with other animals: Reflections on an Australian RSPCA Humane Education Programme
}

\author{
Heather Fraser ${ }^{1}$, Nik Taylor $^{1}$, Tania Signal ${ }^{2}$
}

\begin{abstract}
INTRODUCTION: Empathy is associated with engagement, compassion, social support and emotional sensitivity, and it is a hallmark of good social work practice. Empathy rightfully receives much attention in social work practice, however, interspecies empathy has yet to be included. This article has been written to address this gap.

METHODS: Two main research questions guide our conceptual discussion of young people, interspecies empathy and social work: (1) Why is empathy important to social work with young people?; (2) What can an Australian RSPCA Humane Education Programme (HEP) teach social workers about the benefits of interspecies empathy for young people? After our literature review, we examine our illustrative example, which is an HEP offered mostly to newly arrived refugee and migrant young people living in the outer suburbs of Melbourne, whose prior experiences of and/or attitudes towards animals may not have been positive.

FINDINGS: Social workers are wise to prioritise empathy because extensive research has shown that, across a diverse range of fields, modes of practice in and beyond social work, empathic practitioners are more effective, achieving better outcomes with their clients. From the letters the young people sent to the RSPCA Victoria after completing an HEP, we note their self-reported increases in empathy for animals, including those they had previously feared or shunned.
\end{abstract}

CONCLUSION: There are many potential benefits of recognising, fostering and valuing interspecies empathy through humane education programmes. However, for these to be ethical, care and empathy must be shown towards the wellbeing of the animals involved, not just the human participants.

KEYWORDS: young people; animals; interspecies empathy; refugees; animal cruelty; humane education

Intuitively, many social workers know that children and animals can enjoy each other in profoundly positive ways. Research has consistently found that positive relations with animals can deeply benefit the social, emotional, cognitive and educational growth of children (Arbour, Signal, \& Taylor, 2009; Endenburg \& van Lith, 2011). In particular, humane education programmes (HEPs) have been shown to have multiple benefits across different groups of children and young people. The Jane Goodall Institute (2017, para 1) defines humane education as, “... a process that promotes compassion and respect for all living things by recognising the inter-dependence of people, animals and eco-systems." From their review of international, short-term humane education initiatives, Aguirre and Orihuela (2014) conclude that such programmes can be
${ }^{1}$ Flinders University, Australia

2 Central Queensland University, Australia

AOTEAROA

NEW ZEALAND SOCIAL WORK 29(3), 5-16.

CORRESPONDENCE TO: Heather Fraser h.fraser@flinders.edu.au 
both effective and sustainable over the long term, and that children undertaking such programmes generalise empathy towards animals to humans. This is supported by research demonstrating that HEPs can positively affect children's development of empathy toward both animals and other humans, particularly for those who have experienced some form of abuse (Taylor, Fraser, Signal, \& Prentice, 2016).

Despite the benefits children and young people often derive from relationships with animals, social work has been slow to incorporate the animal turn (Walker, Aimers, \& Perry, 2015), particularly in Australia. In part, this stems from social work's humanist foundations (Evans \& Gray, 2012; Fraser \& Taylor, 2017; Ryan, 2011), but may also be due to an uncertainty about how social workers think about, and treat, interspecies relationships (Evans \& Gray, 2012; Walker et al., 2015). To quote Evans and Perez-y-Perez (2013, p. 16):

... social workers may be poorly equipped to deal with animal-human relationships within the bounds of their professional practice as there is negligible focus on these relationships within social work education and research ...

Ryan's (2014) edited collection, Animals in Social Work: Why and How They Matter, is an exception, providing a range of philosophical and theoretical considerations of animals in social work, before presenting several practical applications, such as the Burke and Iannuzzi chapter on Animal Assisted Therapy for children on the autism spectrum, or the one from Walsh about domestic violence and companion animal welfare (Ryan, 2014). Our article contributes to these discussions through considering the topic of empathic interspecies relationships and the use of humane education programmes. Two main research questions lead our discussion: (1) Why is empathy important to social work with young people?; and (2) What can an RSPCA HEP teach social workers about interspecies empathy?

\section{Methods}

Two methods are used to explore interspecies empathy: a literature review and an analysis of an illustrative example. Our literature review is guided by the question: "Why is interspecies empathy important to social work with young people?" Our illustrative example is examined via the question: "What can an RSPCA HEP teach us about the benefits of interspecies empathy for young people?"

\section{Literature review}

Colloquially speaking, empathy involves trying to "walk in someone else's shoes"; that is, trying to understand how others are feeling, thinking and reacting to circumstances through their eyes. According to de Vignemont and Singer (2006, p. 435):

There is empathy if: (i) one is in an affective state; (ii) this state is isomorphic [similar] to another person's affective state; (iii) this state is elicited by the observation or imagination of another person's affective [feeling] state; (iv) one knows that the other person is the source of one's own affective state.

They note that empathy, " ...motivates cooperative and prosocial behavior, as well as helps for effective social communication" (de Vignemont \& Singer, 2006, p. 435). Gerdes, Lietz, and Segal (2011, p. 85) share this definition of empathy but they stress, "[t]he conscious decision-making to take empathic action." Empathy assists with conflict resolution and plays an important role in addressing inequality and injustice (King, 2011). The pro-social nature of empathy is often emphasised in the belief that early displays of empathy will auger well for people in the future.

Interspecies empathy refers to empathy shown across species, from people to a wide variety of other animals (Nagasawa, Mogi, \& Kikusui, 2009) and in-between species (human and other animal). Interspecies 
empathy can serve as a bridge to many people (Serpell, 2000), including difficultto-reach clients battling the legacy of past abuse, mental health problems, poverty, homelessness and chronic illness. Young or old(er), tough, defensive and angry clients may not be anything like this towards animals (Bathurst \& Lunghofer, 2016), including animals they may have rescued from shelters. Reciprocal benefits can accrue to the humans and other animals that rescue each other, that is, humans rescuing otherwise unwanted and soon-to-be-euthanised shelter animals and shelter animals rescuing humans from their own reports of isolation, loneliness, anxiety and depression (Fraser \& Taylor, 2017).

Extensive research demonstrates links between a lack of empathy and difficulties within inter-human and interspecies relations (Eckardt Erlanger \& Tsytsarev, 2012; Eisenberg, Eggum, \& Di Giunta, 2010). A lack of empathy has been linked to increased proclivities for violence against both humans and other animals, including domestic violence and child abuse (Becker \& French, 2004; Hartman, Hageman, Williams, Mary, \& Ascione, 2016; McEwan, Moffitt, \& Arseneault, 2014; Walker et al., 2015), as well as being tied more broadly to ethically just behaviour (Gruen, 2015). Gruen's (2015) notion of entangled empathy recognises that humans are already entangled in relationships with other animals-often very harmful and exploitative relationshipsbut that this does not need to be the case. Emotional and cognitive, entangled empathy has transformative potential, involving the respect and elimination of enslavement of (other) animals (Gruen, 2015).

The importance placed on empathy by social workers has a long history and is reflected in social work codes of ethics. For instance, in the International Federation of Social Work (IFSW, 2012, Section 5.4) Statement of Ethical Principles, "Social workers should act in relation to the people using their services with compassion, empathy and care."

Empathy is expected to cut across fields and modes of practices, but also theoretical perspectives (see for instance, Fook, 1993; Gerdes et al., 2011; Payne, 2014; Siporin, 1980).

Empathy is described as a core social work value and skill (Stanley \& Bhuvaneswari, 2016) and a hallmark of good practice (Pinderhughes, 1979). We define good social work practice broadly as interventions that produce useful exchanges, and are not, on balance, experienced by clients and observed by others, as unhelpful, unduly controlling, mean-spirited and/or punitive (also see Fook, 1993; Mooney, 2016). Empathy is so important to social work because it directs us towards caring, congruence, interpersonal sensitivity, perspective taking, an appreciation of diversity and ethically oriented behaviours (see Thompson \& Gullone, 2003). It underlies rapport, which is crucial to the sustainability of successful cross- and inter-cultural relationships (see Ramacake, 2010).

Empathy affects how practitioner-client relationships are developed, managed and dissolved. Social workers usually understand that empathy is an intersubjective process that involves trying to understand the plight and contexts of others (Payne, 2014). Contexts matter because they shape the social conventions for empathising with others; they influence the resources dedicated to (or withheld from) those with whom empathy is being expressed; and they mediate whether empathisers are esteemed or denigrated (also see Mooney, 2016). Empathic social workers are aware of the potential empathy has to help others (from managers, workmates, volunteers, clients and social networks) notice, feel and understand aspects of situations that are not always obvious or appreciated. These aspects can be drawn from the (often hidden), back stories (of abuse and neglect, for example), which give context to individual and group experiences. These exploratory processes can occur with clients across age brackets, including young children. Borke (1971) found that children as young as three years 
of age can sensitively respond to other people's moods, such as trying to comfort others when they are sad, angry or upset.

Empathic relationships in social work are as much an art as they are a science. Embodied, affective and cognitive, empathy is the cornerstone of emotional intelligence, and is central to the social work tasks of engaging clients / service, making assessments, collaborating on plans and co-operating with others (Morrison, 2007). Social workers practising with young people are usually aware that empathy is not just built on words but develops also through cultural respect and non-verbal behaviour (see Mooney, 2016) as well as play and fun (see Caroll, 2002). Some therapy clients, especially young clients, report that having fun was the best part of the therapeutic process (Caroll, 2002), the acknowledgment of which has led to the design of alternative, child-centred forms of social work, including animal-centred interventions.

As well as being important in forming good social work practices, and in establishing client-worker relationships, empathy has also been shown to have a healing potential. Empathy is health-enhancing through the sense of belonging and support it can induce. Studying health-enhancing qualities of life, Munford and Sanders (2008) contrasted the experiences of young, marginalised women aged between 13-15 years with those of their more advantaged peers. They found that behaviours labelled troubled and disruptive serve other, important and positive functions for the marginalised women (Munford \& Sanders, 2008). Without empathy, however, the capacity for social workers to reinterpret these behaviours is limited, if not blocked.

Empathy can act as a balm or release to "empathic distress," which Hoffman (2000, p. 4) defines as the distress felt from "...observing someone in actual distressand one or more motives derived from empathic distress: sympathetic distress, empathic anger, empathic feeling of injustice, guilt." By acting empathically, bystanders can help not just others in need, but themselves in the process, to avoid feeling locked in intense, negative emotions. Empathising with others' previous and current experiences of hardship not only helps social workers to engage, but it also allows clients the opportunity to openly reflect on their experiences and find ways to regenerate a sense of belonging and control in their lives (see Mooney, 2016). Empathy helps those who have been abused and traumatised reconnect with, and feel close to, others. Jackson, Frederico, Tanti, and Black (2009), reported that feeling close to others was crucial to abused and traumatised children's attempts at recovery, and management of associated symptoms such as anxiety and depression. As we will suggest later, fun, touch and play characterise many human-animal relationships, across age brackets but particularly for children, and can form powerful conduits for abused children to heal.

Empathy allows us to convey our connections to others but cannot be divorced from hard questions about professional power and clients' rights. For example, De Boer and Coady (2007) interviewed six child welfare workers and their clients and found two key, re-emerging themes for the definition of a good, helping relationship: (1) the "soft" and judicious use of professional power, and (2) a nontraditional professional attitude and style of engagement, that is, more flexible and involves a less authoritative and controlling style of interaction, specifically practitioners negotiating their goals and interests with clients. Without empathic understanding, such a negotiation process is likely to be flawed, if not fraught.

Empathy is crucial to practitioners' critical reflexivity, or the processes and practices deliberately used to understand more about the self and interrogate one's motivations, actions and impact on others. Both empathy and critical reflexivity allow us to adjust our use of self to the needs, interests and preferred styles of those we serve. 
Recognising, working with and regulating emotions (workers and clients) are parts of this process. Children and young people ordinarily understand the importance of the quality of worker-client relationships, which can take time to develop, compared to those that feel robotic and rushed (Ferguson, 2014). Ferguson (2014, p. 8) contrasted this latter style to the social worker who:

...practised in a self-consciously relationship-based manner that was informed by a strength perspective. Her relational style with children and parents was motivational, playful, tactile, yet authoritative and this example typifies how the atmospheres of encounters in such cases were often positive, caring, creative and joyful.

Taking the time to carefully listen to, and be attuned with, clients' perspectives allows practitioners to more accurately understand and empathise with clients, young or old. It also allows for the more dignified appreciation of clients as members of communities that are knowledgeable about their own circumstances (also see Ramacake, 2010). This may be particularly important to those deemed vulnerable, such as children, refugees and asylum seekers.

While there is comprehensive research into the mental and physical wellbeing of adult refugee and asylum seekers (Burnett \& Peel, 2001), there is less about child and/ or adolescent refugee/asylum seekers (Thomas \& Lau, 2002). This is a problem given many young refugees and asylum seekers have spent extended periods in refugee camps and have witnessed and/ or experienced violence, bereavement, dislocation and homelessness prior to re-settlement (Pepworth \& Nash, 2009). In relation to these experiences, young asylum seekers and refugees report high rates of psychological trauma and stress (Murray, Davidson, \& Schweitzer, 2008; Pepworth \& Nash, 2009). Among the many possible service responses to this trauma are carefully designed and run HEPs, which take into consideration the ethics and sensitivities of working with this population (see Elliott, 2015); we now discuss one such programme.

\section{Illustrative example}

To ground our conceptual appreciation of interspecies empathy, we examined a local HEP. Our purpose is to illustrate some of the benefits of inducing interspecies empathy in young people rather than a comprehensive, complete or critical evaluation of the programme operations. Ethics approval was achieved through Central Queensland University (approval number H14/08-186) on the condition that all names would be changed to protect the young people's anonymity, permission was granted for us to review/present these letters.

The RSPCA Victoria CARE ProgramCreating Animal Respect and Empathy - targets new arrivals into Australia who come from English as an Additional Language (EAL) backgrounds, especially refugees and asylum seekers. The programme was developed to both improve animal welfare outcomes and assist students to safely interact with a wide range of animals. The local council region within which the young participants were drawn is considered one of many Australian hotspots of animal cruelty (RSPCA Victoria, 2016).

Participants in the 2014 RSPCA Victoria HEP were secondary students who received four sessions totalling six teaching hours. Facilitators adopted friendly, nonauthoritarian modes of interacting with participants and developed activities based on safe interactions with temperament-tested education dogs, rabbits and guinea pigs. Respectful and kind animal interactions were modelled by RSPCA Victoria Education staff and encouraged in students. For many students this was the first safe and positive interaction with that species of animal. The final session was an excursion to the RSPCA Victoria Education Centre where they met and interacted with a range of farm animals. 
Photographs were taken of the young people interacting with animals. To illustrate more embodied images of the young people but also to maintain anonymity we have described seven images below.

Image 1: A slim young woman with long dark hair, perhaps 14 and originally from the Middle East, stands in a stable beside a chestnut horse smiling happily, casually touching the horse's face. The horse looks on, apparently relaxed.

Image 2: A curly-haired boy, perhaps 13 and from Africa, squats feeding a black-and-white-haired goat. Looking downwards there is a shy pleasure suggested by his smile. Meanwhile a group of other children and adults, all wearing navy fleece jackets and appearing to be visible ethnic minorities, are grouped around the boy, midconversation with each other.

Image 3: Two young women, possibly 15 , stand beside a large brown-and-white cow in a timber barn. The cow, midphotograph sticks out her tongue, much to the girls' amusement. The African girl at the front looks as if she is holding her breath and is a metre from the cow. Her thin friend with dyed red hair, perhaps from Eastern Europe, holds her gaze at the cow's tongue. Her posture seems more relaxed, less hesitant.

Image 4: A white miniature pony stands in a stall surrounded by 13 young people, most of whom were focused on the pony, enticing the animal to eat to allow them to touch him/her. The girl with the red hair stands apart from the group and looks slightly bored.

Image 5: This is a group photograph, posed with 14 young people, four adults, and two longhaired dogs. While the black and white collie sits proudly in the middle, the smaller pomeranian dog is being cuddled by a young Asian Australian girl at the front. Her pleasure is obvious.
Image 6: Sitting in a classroom are two young women, an Asian girl wearing hijab and an African girl who are holding large grey and white rats are smiling into the camera. Both look happy, with the African girl patting the animal in her arms and the Asian girl trying to hold onto a rat in her hands. An Asian young man behind them has his eyes fixed on something not in our view.

Image 7: Eight young people are squatting in a circle, hand-feeding five chickens wandering in the centre. It is cold and all the participants are wearing coats and scarves. Coat-clad torsos of the four adults involved in the programme are standing behind the young people. Of the eight, there are three African Australian boys who all seem amused by the task of feeding the chickens. The three girls wearing hijabs seem to be more shyly contemplative, while one Asian Australian girl, with long, straight dark hair hanging a little in her face, squints, looking either bored or concerned that the chicken she is feeding might peck at her.

These snapshots of interaction (above) are intended to make both the young people and the RSPCA Victoria animals more visible and embodied. Below we analyse the spontaneous, unsolicited, feedback from the students through letters they wrote after the completion of the programme to the RSPCA staff.

\section{Findings}

For this illustrative example, we reviewed 11 letters that participants sent to the RSPCA Victoria after completing the programme. Two of the authors independently read the letters multiple times noting emerging themes. These were then crosschecked and only those noted by both authors were included as guiding categories for analysis. We noted five main themes in the letters: an appreciation of the role of the RSPCA Victoria; an empathic understanding of 
(other) animals; attitudinal changes as result of greater empathy with (other) animals; the importance of touch and interaction for developing interspecies empathy; and the possibility of animals performing the roles of healers, friends and therapists to children and young people.

\section{Appreciating the role of the RSPCA}

As Sofia, one of the young participants in the RSPCA Victoria HEP put it, “... animals have rights like human and we have to take care of them and to feed them because they are living creatures too!" Across the programme, participants expressed their appreciation for the work the RSPCA Victoria does. Consider for instance, Abdul who now appreciated the care animals need and wrote: "Thank you RSPCA ... [for] sharing the information with all of us so that we will be aware of the welfare, the laws of animals ... I want to thank them for giving us this beautiful chance."

\section{Developing an empathic understanding of (other) animals}

Excursions to the RSPCA Victoria centre offered opportunities to develop, not just new knowledge, but also new feelings about animals. To quote Halima:

When we visited RSPCA care centre, I really enjoyed to see beautiful animals have shelter, their life, vet etc. It was amazing and convince[d] me you are right, like animals are humans and now I love animals.

The young people made it clear that learning about animals, being in their presence, and directly interacting with them, helped to shift negative attitudes towards animalsattitudes not conducive to interspecies empathy. For instance, Wardah wrote:

When I started to learn about animals with the RSPCA, I learned how to have fun with animals and about their behaviour and I started to care more about them. I started to like cats as well because before I hated cats and now I changed my mind. I learned how to help them, how to protect them and I have begun to understand them. Now my experience is much better than before, it was a big change and an important experience in Melbourne.

This fits with existing research indicating that the presence of animals in children's classrooms can positively affect social integration (Kotrschal \& Ortbauer, 2003).

\section{Attitudinal change as result of greater empathy with other animals}

The third theme apparent in the analysis was broadly that of change, and more specifically of attitudinal changes, reflecting participants' growing empathy towards animals. This is not surprising given existing studies demonstrating links between empathy for animals and behavioural and/or attitudinal changes, particularly in children (Ascione, 1997; Prokop \& Tunnicliffe, 2008). For many of the children, their visits to the RSPCA Victoria and interaction with the humane educators offered a very different way to think about animals, ways that challenged their existing beliefs. For example, "The excursion to RSPCA is very exciting and let me learn a lot on animals. I can't imagine the importance of animal is so significant before" (Mahmud), and "Now I think animal testing is wrong idea because animals have wrights (sic) (Mohammed). These reported experiences were heartening to the RSPCA Victoria who aim to create programmes that enable children to think differently about other animal species, and derive new meanings to specific kinds of animals (such as farm animals).

Lakestani, Aguirre, and Orihuela (2015), in their analysis of the attitudinal changes brought about in children through humane education initiatives focussing specifically on farm animals found that, as children learnt about non-conventional companion species, 
their designated favourite animals changed. Prior to the intervention, the children named their favourite animals as evenly spread across dogs, cats, farm animals, and other animals. After the intervention they were more likely to name a farmed animal species as their favourite. Importantly, it seems that changing attitudes towards farmed animal species can lead to changes in attitudes towards, and relationships with, companion animal species (TardifWilliams \& Bosacki, 2015). This suggests that including visits to, and teachings about, farmed animal species, as occurred in the present study, might have particular value to HEPs.

Participants wrote about how they experienced their views of animals changing:

I was asking myself why do people like animals? The only thing I was believe is animals are stupid, ugly and always trying to attack the people ... I personally was hate animals.... After came RSPCA I liked animals step by step." (Leo)

Again, this was often contrasted with things they saw in their country of origin, "[animals] ... deserve a lot of respect and consideration because in many countries in Africa the animals are not taken into consideration" (Rita), and, "[i]t was a really great program which teach us many things about animals. First I learned to take care of animals and take them to the vet which is the opposite to my country" (Maya). Being able to interact with animals freely in Australia was seen as a positive:

I have to mention that I didn't spend time with dogs or cats or even rabbits in Iran but I have spent time with horses. In Iran the government police do not allow you to have dogs or cats as pets in the city and a lot of people pay fines because they have dogs with themselves in the city.... Therefore I believe that people in Australia should be really happy because they are allowed to have fun with their pets and they have this freedom. (Ana)

\section{The importance of touch and interaction for developing interspecies empathy}

The tenor of so many of the participants' letters was how uplifting it can be to be part of an empathic, interspecies experience. A common message from the young people was that change could be induced relatively quickly, particularly when experiential opportunities are available to see life through different eyes, for example "Just a few week (sic) with [the] RSPCA's programme, I have a lot of knowledge about animals and they made me realise that animals are our best friend" (Noore). Among some young participants, new-found empathy inspired a longing for new interspecies connections: "Before I was afraid to [sic] dogs. Now I want to have a dog in my house" (Halima).

From the young people's points of view, the programme's success hinged on the opportunities to practise touching animals they had never touched before. Watching adults model engaged and respectful behaviour towards animals showed them how to be with, or approach different species: "I learn how to act with animals.... I love the way you act kindly with your dog" (Maya); and that simply being with other animals makes a difference, "I enjoyed very much meeting the animals" (Leo).

The young participants stressed the importance of being able to meet and touch animals in a safe and protected environment. This first occurred in their own classroom through the help of trained and supervised assistance animals, where RSPCA Victoria facilitators modelled how to approach and touch animals, such as guinea pigs and dogs. They also wrote about how shifting perceptions can open up friendships that were not formerly possible, "I am thankful every [one] who looks after animals and I am strongly saying that animals are friends!!!" (Amir); and again, "Just a few weeks with RSPCA's program, I have had a lot of knowledge about animals and they 
made me realize that animals are our best friend" (Noore). The idea of gaining "a lot of knowledge" may well be linked to improved confidence and self-esteem for the children which, in turn, has been shown to increase with the presence of animals in educational settings (Hediger \& Beetz, 2015).

\section{The possibility of animals performing the roles of healers, friends and therapists to children and young people}

The idea of animals as friends often overlapped with comments about animals as healers and therapists, again, a phenomenon documented in existing research that shows how children often see their companion animals as close friends who they can turn to in difficult times (Kurdek, 2009). As explained by Ana:

When people migrate they have many problems and they are sad because they are starting a new life and learning a new language and it is also a different culture. Therefore it is really good for kids if they just spend time with animals to get rid of the problems and to forget the sadness.

Forgetting (momentarily) about one's sadness through interspecies connections can help young people experience the world around them more positively. It also mirrors research among adult populations that consistently demonstrates companion animals provide social support (McNicholas \& Collis, 2006) and can positively affect the perception of both other people and the individual's environment (Hediger \& Beetz, 2015).

Some children indicated that through relationships with animals as healers and friends, they were better able to settle in Australia:

I don't have words to explain how happy I was [visiting the RSPCA centre]. I left my horses when I came to Australia, which is really hard and I was crying sometimes because I missed them so much. I had fun with them back in Iran and I learned horse riding. When I left Iran I lost them and when you like something and you are forced to leave it, it is the hardest thing to do. However now I have Henry who makes me happy again, he makes me smile and he is one of the most important things in my life because I have found a new life. (Ana)

By connecting with others, including other animals, it is possible to discharge feelings of empathic distress, such as fatalism and helplessness. For instance, Sofia contrasted her previous and current responses to animals' distress:

...if I see the poor animals, the only [thing] I can do is ignore them. However, the RSPCA saves them as well as gives them a real home. This let me feel the world is full of love. I will help animals if they need help now ... [the RSPCA] give the world love and let more and more people know the importance of helping animals.

Having fun and experiencing happiness through empathic interspecies relationships is reported across many demographics, including newly arrived migrants. Focusing on British adults who migrated to Dubai, Walsh and Fox (2011) point out that animals can help people feel a sense of belonging. Early research addressing the roles animals may play in the lives of children who settle in new countries suggests they may offer a safe haven following resettlement because spending time with other animals helps foster a sense of belonging (Riggs, Due, \& Taylor, 2016). Similarly, research also demonstrates how animals can help individuals manage anxiety (Cole, Gawlinski, Steers, \& Kotlerman, 2007), loneliness and depression (Souter \& Miller, 2007).

\section{Conclusion}

We are not suggesting that letters from 11 young participants who undertook one version of the RSPCA Victoria HEP should be taken as universally representative of the 
experiences of all other participants in HEPs. Nor do we wish to imply that there are only benefits to be derived from human-animal interactions. Instead, our use of these letters is simply to illustrate how participants may respond to such programmes, and so happily. Beyond this, our discussion centres on our much broader research question: "Why should social workers care about interspecies empathy?" As we suggest, there are many reasons why the virtual absence of discussion of interspecies empathy in social work, especially Australian social work, is a significant omission. The first relates to the relationship between human and animal abuse.

Beyond social work, there is now a substantial body of research showing connections between violence and abuse directed at both humans and other animals (Arluke, Levin, Luke, \& Ascione, 1999; DeGue \& DiLillo, 2009). Much of this research suggests empathy - or its lackplays a pivotal role (Parkes \& Signal, 2017; Shapiro, 2009). Often termed The Link, research into links between againsthuman and against-animal violence has grown apace over the last two decades and consistently demonstrates that perpetrators of one of these forms of violence are likely to commit abuse against others (Arluke et al., 1999; Becker \& French, 2004), including domestic violence (see DeGue \& DiLillo, 2009; Shapiro, 2009). In a review of the evidence for associations between empathy (human and animal directed) violence and animal cruelty, McPhedran (2009, p. 1) states that, "....animal cruelty, broadly defined and independent of context, interferes with empathy development in children, a process that may affect subsequent attitudes and behaviors including the likelihood of committing acts of violence in adulthood."

ACKNOWLEDGEMENTS: Sally Meakin and Leah Munnery from the Education Team, RSPCA, Victoria. watching and interacting with other beings (see Evans \& Perez-y-Perez, 2013), including farmed and free roaming/wild animals, such as birds, cetaceans and kangaroos (Curtin, 2009). An estimated $50 \%-75 \%$ of households in North America, Europe and Australia contain companion animals and of these, around three-quarters view their animals as family members (Taylor, 2013). Reciprocal expressions of empathy help explain why so many people are able to have such close relationships with companion animals (ordinarily dogs, cats, rabbits, birds, reptiles and chickens), and some are able to connect with animals ordinarily kept on farms (for instance cows and sheep) or allowed to free roam (for instance, kangaroos, emus, dolphins and pelicans). This factor alone makes interspecies empathy a worthy study in social work (also see Evans \& Perez-yPerez, 2013).

An interest in interspecies empathy allows social workers to learn more about the potential and diverse range of health and wellbeing benefits that many humans derive from their empathic animal relationships (also see Evans \& Perez-y-Perez, 2013). The list of potential benefits humans can derive from, and provide to, these (animal) care providers is extensive and well documented and should not be underestimated or ignored (Fraser \& Taylor, 2017). However, there must be empathy for the health and wellbeing of animals involved. Animals should not be used in a purely, or mostly, functional way. Nor should they be roughly handled or treated as objects. They are not tools to use but sentient beings with their own needs and interests. To do otherwise is to model exploitative rather than empathic practices.

\section{References}

Aguirre, V., \& Orihuela, A. (2014). Short-term interventions that accomplish humane education goals: An international review of researcher literature. In R. Jalongo (Ed.), Teaching compassion: Humane education in early childhood (pp. 23-31). Dordrecht Netherlands: Springer Science.

Arbour, R., Signal, T., \& Taylor, N. (2009). Teaching kindness: The promise of humane education. Society \& Animals, 17, 136-148. 
Arluke, A., Levin J, Luke, C., \& Ascione, F. (1999). The relationship of animal abuse to violence and other forms of antisocial behaviour. Journal of Interpersonal Violence, 14(9), 963-975.

Ascione, F. R. (1997). Humane education research: Evaluating efforts to encourage children's kindness and caring toward animals. Genetic, Social \& General Psychology Monographs, 123(1), 57-78.

Bathurst, C. L., \& Lunghofer, L. (2016). Lifetime bonds: At-risk youth and at-risk dogs helping one another. In C. Blazina \& L. R. Kogan (Eds.), Men and their dogs (pp. 133-149). Cham, Switzerland: Springer International Publishing.

Becker, F., \& French, L. (2004). Making the links: Child abuse, animal cruelty and domestic violence. Child Abuse Review, 13, 399-414.

Borke, H. (1971). Interpersonal perception of young children Egocentrism or empathy? Developmental Psychology, 5(2), 263-269.

Burnett, A., \& Peel, M. (2001). Health needs of asylum seekers and refugees. British Medical Journal, 322, 544-547.

Caroll, J. (2002). Play therapy: The children's views. Child \& Family Social Work, 7(3), 177-187.

Cole K. M., Gawlinski A., Steers N., \& Kotlerman, J. (2007). Animal-assisted therapy in patients hospitalized with heart failure. American Journal of Critical Care, 16, 575-585.

Curtin, S. (2009). Wildlife tourism: The intangible, psychological benefits of human-wildlife encounters. Current Issues in Tourism, 12, 451-474.

De Boer, C., \& Coady, N. (2007). Good helping relationships in child welfare: Learning from stories of success. Child \& Family Social Work, 12(1), 32-42.

DeGue, S., \& DiLillo, D. (2009). Is animal cruelty a "red flag" for family violence? Investigating co-occurring violence toward children, partners, and pets. Journal of Interpersonal Violence, 24, 1036-1056.

de Vignemont, F., \& Singer, T. (2006). The empathic brain: How, when and why? Trends in Cognitive Science, 10(10), 435-441.

Eckardt Erlanger, A. C., \& Tsytsarev, S. V. (2012). The relationship between empathy and personality in undergraduate students' attitudes toward nonhuman animals. Society \& Animals, 20, 21-38.

Eisenberg, N., Eggum, N. D., \& Di Giunta, L. (2010). Empathy-related responding: Associations with prosocial behaviour, aggression, and intergroup relations. Social Issues and Policy, 4(1), 143-180.

Elliott, S. (2015). Toward equal participation: An autoethnography of facilitating consultations in the refugee sector. Aotearoa/NZ Social Work Journal, 27(3), 57-67.

Endenburg, N., \& van Lith, H. A. (2011). The influence of animals on the development of children. The Veterinary Journal, 190(2), 208-214.

Evans, N., \& Gray, C. (2012). The practice and ethics of animal-assisted therapy with children and young people: Is it enough that we don't eat our co-workers? British Journal of Social Work, 42(4), 600-617.

Evans, N., \& Perez-y-Perez, M. (2013). Will Marley come home? An exploration of the impacts of the Canterbury earthquakes on people's relationships with their companion animals. Aotearoa New Zealand Social Work, 25(2), 7-17.

Ferguson, H. (2014). What social workers do in performing child protection work: Evidence from research into face-to-face practice. Child \& Family Social Work, 21(3), 283-294.

Fook, J. (1993). Radical casework: A theory of practice. Crows Nest, NSW: Allen \& Unwin.

Fraser, H., \& Taylor, N. (2017). In good company: Women, companion animals and social work. Society \& Animals. Online first. doi:10.1163/15685306-12341450

Gerdes, K. E., Lietz, C. A., \& Segal, E. A. (2011). Measuring empathy in the 21st century: Development of an empathy index rooted in social cognitive neuroscience and social justice. Social Work Research, 35(2), 83-93.

Gruen, L. (2015). Entangled empathy: An alternative ethic for our relationships with animals. Herndon, VA: Lantern Books.

Hartman, C., Hageman, T., Williams, J. H., Mary, J. S., \& Ascione, F. R. (2016). Exploring empathy and callous: Unemotional traits as predictors of animal abuse perpetrated by children exposed to intimate partner violence. Journal of Interpersonal Violence 1-19. Online first. doi:10.1177/0886260516660971

Hediger, K., \& Beetz, A. (2015). The role of human-animal interactions in education. In J. Zinsstag, E. Schilling, D. Waltner-Toews, M. Whittaker, \& M. Tanner (Eds.), One health: The theory and practice of integrated health approaches (pp.73-84). Wallingford, UK: CAB International.

Hoffman, M. L. (2000). Empathy and moral development: Implications for caring and justice. Cambridge, UK: Cambridge University Press.

International Federation of Social Workers (IFSW). (2012). Statement of ethical principles, Section 5.4. Retrieved from http://ifsw.org/policies/statement-of-ethicalprinciples/

Jackson, A., Frederico, M., Tanti, C., \& Black, C. (2009). Exploring outcomes in a therapeutic service response to the emotional and mental health needs of children who have experienced abuse and neglect in Victoria, Australia. Child \& Family Social Work, 14(2), 198-212.

Jane Goodall Institute. (2017). Humane education. Retrieved from http://www.janegoodall.org.au/humane-education/

King, S., Jr. (2011). The structure of empathy in social work practice. Journal of Human Behavior in the Social Environment, 21(6), 679-695.

Kotrschal, K., \& Ortbauer, B. (2003). Behavioral effects of the presence of a dog in a classroom. Anthrozoös, 16, 147-159.

Kurdek, L. A. (2009). Young adults' attachment to pet dogs: Findings from open-ended methods. Anthrozoös, 22, 359-369.

Lakestani, N., Aguirre, V., \& Orihuela, A. (2015). Farm animal welfare and children. Society \& Animals, 23(4), 363-378.

McEwan, F. S., Moffitt, T. E., \& Arseneault, L. (2014). Is childhood cruelty to animals a marker for physical maltreatment in a prospective cohort study of children? Child Abuse \& Neglect, 38(3), 533-543.

McNicholas, J., \& Collis, G. M. (2006). Animals as social supports: Insights for understanding animal-assisted therapy. In A. Fine (Ed.), Handbook on animal-assisted 
therapy: Theoretical foundations and guidelines for practice ( $2^{\text {nd }}$ ed., pp. 49-72). Amsterdam, Netherlands; Boston MA: Academic Press, Elsevier.

McPhedran, S. (2009). A review of the evidence for associations between empathy, violence and animal cruelty. Aggression \& Violent Behavior, 14(1), 1-4.

Mooney, H. (2016). Māori social work views and practices of rapport building with rangatahi Māori. Aotearoa New Zealand Social Work, 24(3-4), 49-64.

Morrison, T. (2007). Emotional intelligence, emotion and social work: Context, characteristics, complications and contribution. British Journal of Social Work, 37(2), 245-263.

Munford, R., \& Sanders, J. (2008). Drawing out strengths and building capacity in social work with troubled young women. Child \& Family Social Work, 13(1), 2-11.

Murray, K., Davidson, G. R., \& Schweitzer, R. D. (2008). Psychological wellbeing of refugees resettling in Australia. Literature review prepared for the Australian Psychological Society. Retrieved from https://www.psychology.org.au/assets/files/refugee-litreview.pdf

Nagasawa, M., Mogi, K., \& Kikusui, T. (2009). Attachment between humans and dogs. Japanese Psychological Research, 51(3), 209-221.

Parkes, D., \& Signal, T. (2017). Revisiting a link: Animal abuse, bullying and empathy in Australian youth. Human-Animal Interaction Bulletin, 5(1), 26-40.

Payne, M. (2014). Modern social work theory. $4^{\text {th }}$ ed. Basingstoke, UK: Palgrave Macmillan.

Pepworth, J., \& Nash, M. (2009). Finding "a safe place to cry": A review of research and evidence informing social work with refugees and new settlers in Aotearoa New Zealand. Aotearoa New Zealand Social Work Review, 21(1\&2), 48-59.

Pinderhughes, E. B. (1979). Teaching empathy in crosscultural social work. Social Work, 24(4), 312-316.

Prokop, P., \& Tunnicliffe, S. D. (2008). "Disgusting" animals: Primary school children's attitudes and myths of bats and spiders. Eurasia Journal of Mathematics, Science \& Technology Education, 4(2), 87-97.

Ramacake, S. (2010). Fijian social work practice. Aotearoa New Zealand Social Work, 22(4), 38-43.

Riggs, D. W., Due, C., \& Taylor, N. (2016). "I want to bring him from the aeroplane to here": The meaning of animals to children of refugee or migrant backgrounds resettled in Australia. Children \& Society. Online first. doi:10.1111/ chso.12196

Royal Society for the Prevention of Cruelty of Animals (RSPCA) Victoria. (2016, August 30). RSPCA Victoria Releases Animal Cruelty Hotspot Data. [Media release].

Ryan, T. (2011). Animals and social work: A moral introduction. Basingstoke, UK: Palgrave Macmillan.

Ryan, T. (Ed.). (2014). Animals in social work: Why and how they matter. Basingstoke, UK: Palgrave Macmillan.

Serpell, J. A. (2000). Creatures of the unconscious: Companion animals as mediators. In A. Podberscek, E. Paul \& J. A. Serpell (Eds.), Companion animals and us: Exploring the relationship between people and pets (pp. 108-124). Cambridge, UK: Cambridge University Press.

Shapiro, K. (2009). People and animals, kindness and cruelty: Research directions and policy implications. Journal of Social Issues, 65(3), 569-587.
Siporin, M. (1980). Ecological systems theory in socia work. The Journal of Sociology \& Social Welfare, 7(4), 507-532.

Souter, M. A., \& Miller, M. D. (2007). Do animal-assisted activities effectively treat depression: A meta-analysis. Anthrozoös, 20, 167-180.

Stanley, S., \& Bhuvaneswari, G. M. (2016). Reflective ability, empathy, and emotional intelligence in undergraduate social work students: A cross-sectional study from India. Social Work Education, 35(5), 560-575.

Tardif-Williams, C. Y., \& Bosacki, S. L. (2015). Evaluating the impact of a humane education summer-camp program on school-aged children's relationships with companion animals. Anthrozoös, 28(4), 587-600.

Taylor, N. (2013). Human, animals and society: An introduction to human-animal studies. New York, NY: Lantern Books.

Taylor, N., Fraser, H., Signal, T., \& Prentice, K. (2016). Social work, animal assisted therapies and ethical considerations: A case example from Central Queensland. British Journal of Social Work, 46(1), 135-152.

Thomas, T., \& Lau, W. (2002). Psychological well being of child and adolescent refugee and asylum seekers: Overview of major research findings of the past ten years. Review prepared for National Inquiry into Children in Immigration Detention. Retrieved from https://www.humanrights.gov.au/publications/ psychological-well-being-child-and-adolescent-refugeeand-asylum-seekers

Thompson, K. L., \& Gullone, E. (2003). Promotion of empathy and prosocial behaviour in children through humane education. Australian Psychologist, 38(3), 175-182.

Walker, P., Aimers, J., \& Perry, C. (2015). Animals and social work: An emerging field of practice for Aotearoa New Zealand. Aotearoa New Zealand Social Work, 27(1/2), 24-35.

Walsh, K., \& Fox, R. (2011). Furry belongings: Pets, migration and belonging. In J. Bull (Ed.), Animal movements, moving animals: Essays on direction, velocity and agency in humanimal encounters. Uppsala, Sweden: Centre for Gender Research. 